\title{
Study on the Effect of Entrepreneurship on the Business Performance of Small and Medium Enterprises: A Case Study in Vietnam
}

\author{
Thân Thanh Sơn, Bùi Thị Thu Loan*, Đỗ Hải Hưng, Trần Thị Hoa \\ School of Business Management, Ha Noi University of Industry, Vietnam
}

Received February 17, 2020; Revised April 21, 2020; Accepted May 3, 2020

Copyright $\bigcirc 2020$ by authors, all rights reserved. Authors agree that this article remains permanently open access under the terms of the Creative Commons Attribution License 4.0 International License

\begin{abstract}
The literature on entrepreneurship suggests that entrepreneurial orientation (EO) improves business performance, while the empirical results are mixed. Therefore, this study focuses on determining the impact of this relationship on the sample of small and medium enterprises in the context of emerging economies and transformation based on the results of a survey of 113 enterprises in Hanoi, Vietnam. Using multivariate regression analysis after testing the reliability of the scale, the research results provide evidence that enterprises in the practicing higher EO obtains better business results than those implementing low EO strategies. This result is validated even in business environments considered benign, in which the influence of the environment regulates the relationship between EO and operational efficiency. However, this initial research on entrepreneurial tendencies only confirms that only two of the three aspects of EO have a positive effect on operational efficiency, including proactiveness and risk-taking initiatives. Nevertheless, these results also suggest that, in the context of transitioning economies, where most of the businesses are active in the field of trade in services, innovation orientation is not a factor that has a direct impact on improving business performance. This result does not negate the role of innovation, but implies the direction of future research as mentioned in the paper.
\end{abstract}

Keywords Entrepreneurship, Small and Medium Enterprises (SMEs), Business Environment, Performance

\section{Introduction}

Research on the factors affecting business performance of firms is always the subject of attention of both researchers and business executives, as profitability and profit scale are important foundations for enterprises to accumulate capital to re-invest, thus expand business operation, improve competitiveness and be able to cope with external shocks from the market. This is significant for recent small and medium enterprises in Vietnam because this sector accounts for $97 \%$ of the total number of businesses and plays an important role in economic growth. However, most operating firms are small to micro- small which have very low profitability and are very vulnerable. Therefore, a lot of existing studies revolving around examining which factors have a positive effect on the profitability of businesses, especially in the current period, where exists a general trend in the business environment, which is a shortening of the product / business life cycle (Hamel, 2000). As a result, future revenue from existing activities are uncertain and businesses need to constantly look for new opportunities.

The benefits of new opportunities for SMEs can be derived from the application of entrepreneurial orientation (EO). This involves being willing to innovate to be more compatible with current market requirements, taking risks to test new products, services and markets with uncertainty, and be more proactive than competitors towards new market opportunities (Covin and Slevin, 1991). This concept proposed by Covin and Slevin (1991) is supported by empirical evidence in the literature. Studies have found that enterprises applying more business strategy orientations have better operational efficiency (Wiklund, 1999; Zahra, 1991; Zahra and Covin, 1995).

However, the empirical results related to this relationship so far do not have a general agreement. While quite a few studies confirm a positive relationship between entrepreneurship and business performance, some empirical evidence from other studies does not support this 
claim. For example, a study by Smart and Conant (1994), unable to find a significant relationship between EO and performance and Hart (1992) argued that the type of business strategy with EO direction in uncertain conditions may even be associated with poor performance. Although differences in findings may be attributable to differences in research design or methodology, this clearly reflects the fact that EO does not always contribute to improved operational efficiency.

In addition, existing studies also show the complexity and multidimensional nature of this relationship. Lumpkin and Dess (1996) suggest that the degree of influence in EO and operational performance relationship is contextual. The intensity of this relationship depends on the characteristics of the external environment as well as internal organizational characteristics. Therefore, the relationship between EO and performance obviously cannot be merely a relationship with only major influences, but the direction and level of influence can bring the characteristics of each specific economic context.

Considering the above issues, the question raised in this study is that in the context of the transition economy in Vietnam, when the business ecosystem has had positive changes recently in the direction of promoting the entrepreneurial spirits in private sector, rather than focusing on state-owned enterprises as in the previous periods, how is this unilateral relationship expressed? Specifically, we offer two main research questions:

1. In the context of transition economy, how does EO affect the performance of small and medium-sized enterprises?

2. Is this relationship affected by the characteristics of the environment in which businesses operate?

To answer this question, we assess the impact of entrepreneurship correlation on the performance of SMEs, while also considering the impact of environmental factors on this relationship based on analysis of data from a sample of 113 SMEs in Hanoi, Vietnam.

With the initial results obtained from empirical analysis of the impact of EO on performance of SMEs, our findings contribute to the existing literature on clarifying the mechanism of impact of each aspect of EO to performance of SMEs as well as the influence of the environmental characteristics in which the business operates. In addition, the study also provides practical application implications for the issue of innovation, proactive pioneer and risk taking in relation to business performance of enterprises, when studies related to this issue are rather scarce in the context of Vietnam's economy at present.

The following sections of this study include: (2) Literature review and hypotheses; (3) Research methods and models; (4) Research results and (5) Discussion and implications.

\section{Literature Review and Hypotheses}

\subsection{Entrepreneurship Orientation (EO) and Performance}

Entrepreneurship is a concept that refers to the strategy orientation of the business. In his research, Miller (1983) summarizes entrepreneurship at the enterprise level based on the connection of three factors: Innovation, initiative and risk taking. In which, product innovation refers to the possibility that a company can create a new product or modify an existing product to meet the needs of current and future markets. Proactivity refers to the ability of a business to beat competitors in introducing new products, services or new technologies to the market. The risk-taking aspect is reflected in the willingness of enterprises to participate in business strategies and projects with uncertainty about outputs.

As such, EO relates to the willingness to meet current market requirements to test new products and services with greater uncertainty and initiative than competitors in moving towards new market opportunities. (Covin and Slevin, 1989, 1990, 1991; Knight, 1997; Miller, 1983; Namen and Slevin, 1993; Wiklund, 1999; Zahra and Covin, 1995; Zahra, 1993a). Because of this feature, entrepreneurship is considered an important factor for business success (Vij, S., and Bedi, HS, 2012), especially for SMEs (Keh, Hean. Tat, Nguyen Thi Tuyet Mai, \& Hwei Ping Ng. 2007; Wang, K. Y et al., 2015).

In Vietnam, the role of entrepreneurs and entrepreneurship orientation have also been considered in recent studies (Nguyen Van Thang, 2001; Thai Thanh Ha, 2003; Nguyen Thi Tuyet Mai 2008; Nguyen Thi Tuyet Mai, 2010; Nguyen Thi Tuyet Mai, 2011). However, existing studies are mainly focused on clarifying the framework of entrepreneurship issues appropriate to the relatively new economic context in Vietnam and to identify the role of entrepreneurship orientation in business performance based on the implications instead of directly examining this relationship. However, these studies can be considered as the ones that pave the way for the experimental examination of the influence of entrepreneurship on performance. In fact, the relation between EO and business performance can be deduced primarily from existing qualitative and case studies. For example, some studies suggest that companies pioneering the creation and introduction of new products or technologies may be typical companies that implement EO, often achieving far better financial results. (Cheney, Devinney, and Winer 1991; Lengnick-Hall 1992). It is the pioneering that helps businesses to control market access, dominate distribution channels and establish standard products, thereby helping businesses achieve high market shares, sustainably and profitably by enhancing the competitiveness of enterprises (Zahra and Das 1993). Relating to each specific aspect of entrepreneurship and relationship to firm performance, we 
develop the following research hypotheses:

First, for the innovation aspect of entrepreneurship embodied by the tendency to engage and support new ideas, novelty, tests and creative processes rooted in practical requirements or stemming from requirements set up under a new technological system for products and services (Lumpkin and Dess, 1996). With breakthrough initiatives, companies that innovate, create and introduce new technology can create outstanding performance and are seen as the engine of growth (Schumpeter, 1934; Brown and Eisenhardt, 1998). In countries with a developing economy like Vietnam, businesses, especially state-owned businesses still conduct their operation according to the characteristics of a transition economy (from a centrally planned economy to a market oriented economy), and this is regarded as a slow response to changes. While the private sector is quite dynamic, the resources for innovation and creativity are still limited. Nevertheless, in the age of integration, if a business fails to upgrade itself to adapt to changes in the market demands for products and services through its business practice, quality and product/service diversity, it cannot fulfill the market demands in the present and future. Therefore, businesses focusing their resources and management on renovation will acquire more opportunities to increase sales and profit. Therefore, the study proposes the hypotheses on the impact of innovation on the business performance of small businesses as follows:

H1: Innovation has a positive impact on the business performance of small and medium enterprises

Second, entrepreneurship is represented by the initiative to demonstrate a predictable way of doing business and to act based on the needs and desires of the market, thereby creating the advantages of the pioneers compared to competitors (Lumpkin and Dess, 1996). Under this approach, proactive businesses aspire to be pioneers, thus seizing new opportunities. This is the factor that helps businesses increase their competitiveness and thereby increase the business efficiency of the business from the advantage of its predecessors (Zahra and Covin, 1995). The general trend in the current business environment is the shortened business life cycle and product life cycle (Hamel, 2000), thereby reduces the certainty of future revenue streams from existing activities. Therefore, the initiative helps businesses gain access to new opportunities, helping to ensure more business efficiency in the modern economy. In the context of a transition and developing economy with a densely populated country and a young population like Vietnam, the market is seen as being potential with available opportunities for investors in certain product and service segments, especially niche markets. Therefore, an enterprise that carries out EO in a proactive, daring and leading manner will obtain the advantage of taking control of certain market segments, creating an initial distribution channel, which is the basis for improving business efficiency. In other words, this bold, proactive activity gives pioneers in an emerging economy the opportunity to enter the market to achieve high sales and sustainable profits. Conservatively, leading-edge activities can also face certain risks due to new market access /entry costs for building distribution systems, brand recognition, and also taking into account the simultaneous appearance of competitors. However, a study by Zahra and Das (1993) has suggested that pioneering often allows an enterprise to create a mechanism to reshape industry boundaries and rules for competing, especially in an environment of fierce competition. Therefore, this generally helps increase the competitiveness of the business, giving it the opportunities to achieve outstanding business efficiency if it does not fall into the wrong strategic direction. Based on this argument, the hypothesis of a positive relationship between initiative and business performance is proposed as follows:

H2: The proactiveness has a positive effect on the business performance of small and medium enterprises

Third, the risk-taking aspect involves a willingness to commit more resources to projects (Miller and Friesen, 1982). Businesses that are risk averse will consider pursuing existing safety projects and continue to do well with their existing market-accepted products and services. In the meantime, among opportunities, they may abandon projects with high uncertainty or limit resources in order to minimize unforeseen failure costs. In contrast, proactive businesses will not be afraid to attempt and invest in unknown and sure projects.

In some cases, the relation between risk-taking and business performance is seen to lack clarity. Research (March, 1991; McGrath, 2001) suggests that while trial and error strategies can lead to high average earnings, risk strategies lead to volatility in earnings because some projects fail while others succeed with greater profitability in the long term. Nevertheless, risk taking (but not arbitrarily) in certain extent along with risk management can support resources for business development in seizing new opportunities so that businesses can get higher business performance.

In addition, in Vietnam's context of a developing economy, with average income, the accumulation capacity of small and medium enterprises is considered limited. Furthermore, small and medium enterprises face multiple challenges in trying to gain access to the bank's credit capital, so the participation in risky investment projects and opportunities is often based on the equity or bank loans with strict credit terms. Therefore, high-risk investment decisions have been taken into account by businesses on the basis of calculating opportunities and risks with the expectation of achieving superior performance.

Therefore, we hypothesize that:

H3: Risk- taking has a positive effect on the business performance of small and medium enterprises

As such, entrepreneurship can support businesses in the process through aspects of innovation, creativity and risk 
taking, which can have a positive effect on business performance. (Wiklund, 1999; Zahra, 1991; Zahra and Covin, 1995). In an overarching structure, we believe that entrepreneurship has a positive influence on the business performance of firms.

\subsection{The Interaction of Entrepreneurship with the Environment}

The study (Covin and Slevin 1991) suggests the impact of the business environment on the level of success of EO practice in businesses. These factors can be industry-specific competition, business field, industry globalization level, cycle characteristics, product lifecycle and legal requirements by State administration.

This study also focuses on the initial identification of the effects of external impacts on the relationship between entrepreneurship and business performance based on the suggestion of Zahra (1993). Accordingly, the environments considered to be highly disadvantageous are characterized by high competitiveness, and/or contain many uncertainties related to the market and products. At that time, the hostile environment is likely to offer fewer opportunities for achieving growth and profitability. At that time, EO settings helped to bring competitiveness beyond businesses pursuing EO strategy in benign environmental conditions (Covin and Slevin, 1991). Consistent with these debates, many empirical studies have also found that businesses with high EO implementation have the best results in hostile environments while businesses that show low levels of EO are often present in benign environments. Therefore, the harshness of the business environment can regulate the relationship of EO and operational efficiency. Based on these arguments, we propose the same hypothesis suggested by Covin and Slevin, (1991) as follows:

H4: The relationship between EO and performance is more positive between businesses in hostile environment than those in benign, less competitive environment

This hypothesis is also consistent with results from empirical studies that support the claim that the effect of EO on business performance varies across different external environments (Covin and Slevin, 1989; Namen and Slevin, 1993; Zahra and Covin, 1995; Zahra, 1993b) and the various resources within each enterprise. (Brush et al., 2001).

\section{Methodology}

\subsection{Variables and Measures}

\subsubsection{The Performance of Small and Medium Enterprises}

In order to capture the aspects of business performance of SMEs, we connect the assessment scale based on firms' growth together with self-reported assessments of gross profit and profit margin. On this scale, respondents were asked the profit and turnover status as well as the profit margin calculated according to the ratio of profit to sales. These scales are self-assessed by the respondent and estimated on a 5-level Likert scale. In particular, the scales include evaluation indicators compared to competitors. The questions are anchored based on statements from "much less than competitors" to "much more than competitors".

Using business performance scales as a proxy for growth and competitiveness to a certain extent is considered to be more accurate and accessible than accounting scales. Therefore, these scales are commonly used in most related studies (Brush and Vander Werf, 1992; Chandler and Hanks, 1993; Fombrun and Wally, 1989; Tsai et al., 1991).

\subsubsection{Entrepreneurship Orientation}

Table 1. Measurement scale for entrepreneurship

\begin{tabular}{|l|l|}
\hline Variables & \multicolumn{1}{|c|}{ Items } \\
\hline \multirow{1}{*}{ EO } & $\begin{array}{l}\text { 1. Our company has introduced many new products } \\
\text { or services over the past 3 years }\end{array}$ \\
\hline $\begin{array}{l}\text { 2. Our company has made many dramatic changes in } \\
\text { the mix of its product and service over the past 3. }\end{array}$ & $\begin{array}{l}\text { 3. Our company has focused on significant } \\
\text { innovation in products and services over the past 3 } \\
\text { years }\end{array}$ \\
\cline { 2 - 3 } & $\begin{array}{l}\text { 4. Over the past 3 years, the company has shown a } \\
\text { strong tendency to lean towards high-risk projects } \\
\text { (with very high profit changes) }\end{array}$ \\
\cline { 2 - 3 } & $\begin{array}{l}\text { 5. The company has focused on taking bold and } \\
\text { widespread actions in positioning businesses and } \\
\text { products and services in the past 3 years. }\end{array}$ \\
\cline { 2 - 3 } & $\begin{array}{l}\text { 6. Our company has shown a strong commitment to } \\
\text { research and development (R\&D), technological } \\
\text { leadership and innovation. }\end{array}$ \\
\cline { 2 - 3 } & $\begin{array}{l}\text { 7. Our company has pursued strategies that allow } \\
\text { exploring opportunities in the external environment }\end{array}$ \\
\hline $\begin{array}{l}\text { 8. When making business decisions in the context of } \\
\text { uncertainty, our business often has a careful, "wait } \\
\text { and see" attitude to minimize making wrong } \\
\text { decisions. }\end{array}$ \\
\hline
\end{tabular}

Miller's original scale (1982) for EO includes 8 indicators used in combination with some adjustments to suit the research context based on the indicators proposed by (Nguyen Thi Tuyet Mai and Bui Anh Tuan, 2018, Nguyen Thi Tuyet Mai, 2015). This EO scale has been widely used in past studies because of its reliability and validity (Zahra 1991). These indicators are a mandatory type of question, with pairs of opposite statements. The 5 -level scale is divided into 2 types of statements from "strongly disagree" to "strongly agree" for each statement. Table 1 demonstrates items representing three dimensions of entrepreneurship orientation based on the original scales proposed by Zahza and Covin (1995) and some essential adjustments suitable to the context in Vietnam. In order to avoid answers set by confounding factors (the desire to achieve entrepreneurship), questions were organized so 
that statements about entrepreneurship and no entrepreneurial spirit appeared both right side and left side. In the current study, reports have acceptable reliability with the value of Cronbach Alpha greater than 0.6.

\subsubsection{Sample, Data and Analytical Methods}

Our study was conducted through a survey of 150 SMEs operating in Hanoi based on the list of 445 SMEs used in 2016 PCI investigation by the Vietnam Chamber of Commerce and Industry (VCCI), selected using the random cascading method. The questionnaire is designed for business managers (directors or business owners). The scales used in previous studies in Vietnam (09 indicators measuring 03 aspects of entrepreneurship) were inherited and included in the questionnaire. These scales have been implemented according to the forward and reverse translation process. In order to conduct data collection, we first performed a test of accuracy, clarity and coherence with the support of experts in the field of research. Next, we conducted a small sample survey with the purpose of completing the questionnaires to ensure accuracy and comprehension through direct surveys by interview.

Table 2. Information of survey respondents

\begin{tabular}{|c|c|c|c|}
\hline \multicolumn{2}{|c|}{ Business information } & Number & Percentage \\
\hline \multirow{4}{*}{ Industry } & $\begin{array}{c}\text { Industrial } \\
\text { manufacture }\end{array}$ & 12 & $10.6 \%$ \\
\cline { 2 - 4 } & Trading services & 75 & $66.37 \%$ \\
\cline { 2 - 4 } & Transport & 5 & $4.4 \%$ \\
\cline { 2 - 4 } & Construction & 18 & $15.92 \%$ \\
\cline { 2 - 4 } & Agriculture & 3 & $2.65 \%$ \\
\hline \multirow{3}{*}{ Ownership } & $\begin{array}{c}\text { Business has state } \\
\text { funding }\end{array}$ & 6 & $5.3 \%$ \\
\cline { 2 - 4 } & Private business & 107 & $94.6 \%$ \\
\hline Size & $<50$ employees & 108 & $95.5 \%$ \\
\hline & $>100$ employees & 5 & $4.5 \%$ \\
\hline
\end{tabular}

During the survey, we emphasize that there is no right or wrong answer but only the judgments of the company based on practical activities to avoid the risk of bias according to the wishes of the respondents. The collected data includes information for both independent and dependent variables. The total number of responses to the questionnaires that can be used for analysis is 113 observations. The information collected from the surveyed businesses ensures the requirements of the sampling frame. Respondents currently operate in all 5 areas, but mainly fall into the field of trading services on a small scale, with the operation time of over 3 years. The details of surveyed enterprises are presented in Table 2. The number of questionnaires was not recorded because the enterprises did not cooperate to answer or the information on the questionnaire was not valid.

We report the results of analysis based on linear regression analysis of the effect of EO on operational efficiency in section 4. Accordingly, we first check the reliability of the scale according to Cronbach Alpha coefficient $>0.7$ for variables. The rotated component matrix is tested to ensure the convergence validity and discriminant validity of the indicators for each scale. The reporting model used for analysis ensures the necessary tests for multicollinearity and autocorrelation through testing the variance inflation factor (VIF) $<2$ (Table 3) and Durbin - Waltson test at the value $1.899(<3)$ does not violate the assumption of autocorrelation. The above contents are implemented on SPSS 22 software.

\section{Research Results}

\subsection{Reliability of Scales}

After removing an indicator (CR3) at the risk-taking variable due to the corrected item- total correlation $<0.3$, the Cronbach's Alpha coefficient of the variables represents innovation, proactive pioneering and risk taking are respectively $0.741,0.711$ and 0.753 (Table 3 ). These values ensure that the scales can be used in the analysis of the study. With this result, the measurement indicators for each conceptual variable are accepted and used in factor analysis at the next step. 
Table 3. Results of assessing the reliability of the scale

\begin{tabular}{|c|c|c|c|c|}
\hline & $\begin{array}{c}\text { Scale Mean if Item } \\
\text { Deleted }\end{array}$ & $\begin{array}{c}\text { Scale Variance if Item } \\
\text { Deleted }\end{array}$ & $\begin{array}{c}\text { Corrected Item-Total } \\
\text { Correlation }\end{array}$ & $\begin{array}{c}\text { Cronbach's Alpha if Item } \\
\text { Deleted }\end{array}$ \\
\hline \multicolumn{5}{|c|}{ 1. Innovation (Cronbach's Alpha $=0,741)$} \\
\hline DM1 & 7.21 & 1.847 & .402 & .768 \\
\hline DM2 & 7.48 & 1.395 & 630 & .487 \\
\hline DM3 & 7.58 & 1.622 & .573 & .570 \\
\hline \multicolumn{5}{|c|}{ 2. Proactive pioneer $($ Cronbach's Alpha $=0,711)$} \\
\hline CD1 & 6.06 & 1.594 & .737 & .438 \\
\hline $\mathrm{CD} 2$ & 6.18 & 1.718 & .578 & .646 \\
\hline CD3 & 6.33 & 2.347 & .414 & .812 \\
\hline \multicolumn{5}{|c|}{ 3. $\quad$ Risk -taking $($ Cronbach's Alpha $=0,753)$} \\
\hline RR1 & 6.02 & 1.607 & .506 & .439 \\
\hline RR2 & 5.63 & 1.753 & 612 & .280 \\
\hline RR3 & 6.60 & 2.706 & .248 & .753 \\
\hline
\end{tabular}

After removing an indicator (CR3) at the risk-taking variable due to the corrected item- total correlation $<0.3$, the Cronbach's Alpha coefficient of the variables represents innovation, proactive pioneering and risk taking are respectively $0.741,0.711$ and 0.753 (Table3). These values ensure that the scales can be used in the analysis of the study. With this result, the measurement indicators for each conceptual variable are accepted and used in factor analysis at the next step.

The result of factor analysis test with KMO index of $0.754>0.5$ shows that the data used for factor analysis is appropriate. Barlett's test result of 332,661 with p-value = 0.000 indicates that the variables are correlated and satisfy factor analysis conditions.

\subsection{Results of Regression Analysis and Discussion}

Table 4. ANOVAa

\begin{tabular}{|c|c|c|c|c|c|}
\hline Model & $\begin{array}{c}\text { Sum of } \\
\text { Squares }\end{array}$ & Df & $\begin{array}{c}\text { Mean } \\
\text { Square }\end{array}$ & F & Sig. \\
\hline Regression & 356.535 & 7 & 50.934 & 9.4 & $.000^{\mathrm{b}}$ \\
\hline Residual & 568.032 & 105 & 5.410 & & \\
\hline Total & 924.566 & 112 & & & \\
\hline
\end{tabular}

a. Dependent Variable: HQKD

b. Predictors: (Constant), Size, Age, Take- risk, Environment TT, Proactiveness, Innovation, Environment

The regression analysis model, exploratory factor analysis (EFA) is significant with the test value of the conformity of model $F=9,415$ (Sig. 000) with the participating variables in the model including the independent variables representing three aspects of the EO, the control variables of the size and age of the business and the interaction variables representing the benign or hostle level of business environment in which a business is operating.

The average variance extracted result of the model also reaches the required value above $50 \%$ (56.508\%). The adjusted R2 value of the model is $34.5 \%$. The model does not violate the assumption of autocorrelation and multicollinearity. Analysis results are reported in the table 4.

The regression analysis results show that EO is basically a strategic configuration that has a positive effect on the business performance (Table 5). However, when considering the impact of each specific aspect of EO on performance, only hypothesis $\mathrm{H} 2$ and $\mathrm{H} 3$ are supported. In other words, the factors of initiatives and risk-taking has a positive effect on the business performance. The impact coefficient of these aspects in turn according to the standardized Beta are 0.331 and 0.195 . These values indicate that, on average, in the sample, a change of $1 \%$ in the level of boldness, leadership, and risk taking can lead to a $0.33 \%$ and $0.19 \%$ increase in business performance, respectively. The statistics also show that between the pioneering and risk-taking aspects, risk-taking seems to have less of an impact on the business performance of SMEs than boldness and pioneering. This result is also consistent with findings in the study of the relationship between EO and firm performance in both developed countries (Wiklund J and Shepherd, 2015; Acosta, 2018) and countries with an emerging and transition economy (Hughes. P et al, 2018; Gao Y et al, 2018). 
Table 5. The effect of EO on the performance of small and medium enterprises Coefficients ${ }^{\mathrm{a}}$

\begin{tabular}{|c|c|c|c|c|c|c|c|}
\hline \multirow{2}{*}{ Model } & \multicolumn{2}{|c|}{ Unstandardized Coefficients } & \multirow{2}{*}{$\begin{array}{c}\begin{array}{c}\text { Standardized } \\
\text { Coefficients }\end{array} \\
\text { Beta }\end{array}$} & \multirow{2}{*}{$\mathrm{T}$} & \multirow{2}{*}{ Sig. } & \multicolumn{2}{|c|}{ Multicollinearity Statistics } \\
\hline & Beta & Std. Error & & & & Tolerance & VIF \\
\hline (Constant) & 8.571 & 2.012 & & & .000 & & \\
\hline Innovation & .197 & .163 & .122 & & 4.259 & .570 & 1.755 \\
\hline Proactiveness & .490 & .132 & .331 & 3.710 & 1.205 & .735 & 1.360 \\
\hline Risk - taking & .286 & .129 & .195 & 2.219 & .029 & .757 & 1.321 \\
\hline Environment & -1.231 & .658 & -.213 & -1.871 & .064 & .451 & 2.218 \\
\hline Environment_TT & .065 & .022 & .317 & 2.999 & .003 & .525 & 1.904 \\
\hline Age & -.509 & .226 & -.179 & -2.248 & .027 & .923 & 1.083 \\
\hline Size & .042 & .100 & .033 & .424 & .672 & .992 & 1.008 \\
\hline
\end{tabular}

a. Dependent Variable: Performance

These results show that the context of globalization affects the change of business thinking of small and medium enterprises in countries with transition economies. Accordingly, businesses that change in the direction of meeting the demands of the current market by being proactive and pioneering access to new market segments to achieve relatively higher business performance compared to businesses that lack initiatives and only operate in familiar markets that have been previously established. Here, our research focuses on the domestic market rather than the international market. In addition, pioneering really allows businesses to create a mechanism to reshape industry boundaries and competition rules to by taking the first-mover advantages over its competitors to achieve higher business performance. Similarly, the results show that firms that dare to take risks can achieve higher business performance because they can make use of their resources to seize the first investment opportunities in uncertain business conditions. The results also suggest that: (1) - a developing economy that requires significantly more financial resources for new business opportunities is a good condition for obtaining more impressive business results, and (2) - SMEs need to be able to set up dynamic capabilities to identify the opportunities present and respond quickly to them. (Knight and Liesch, 2016).

While the theoretical expectation would state that innovation in businesses is a competitive advantage by maintaining customers' loyalty and a connection beneficial to business performance, the analysis results in this study do not provide evidence that innovation is a factor that has a positive impact on performance of SMEs although the influence of this relationship is recognized. This result is not supported by existing studies of positive relationships that have been confirmed in different contexts and even in the scope of small and medium enterprises. Our explanation for this is that the current studies on existing EO strategies, even in the context of emerging economies, mainly look at the sample of manufacturing firms. The specificity of this research sample allows the measure of the level of innovation clearly through innovation in machinery, equipment, application of new technologies as well as the level of investment in research and development (R\&D). However, in our research sample, enterprises in Vietnam as presented in the above content are, essentially, businesses operating in the field of trade in services, so the extent of innovation has not been clearly shown. This may be one of the reasons that the current study could not help confirm a positive and statistically significant relationship between innovation and business efficiency.

When considering the impact of the environment this result confirms the interactive relationship between $\mathrm{EO}$ and performance at a $10 \%$ significance level but does not support the hypothesis H4. The result shows that businesses in benign environments that are creative, proactive, and dare to take risks still achieve better business performance than businesses that perform EO in harsh environments. This result is in contrast to the research of Zahza and Covin (1995), but suitable for the case of small and medium enterprises in the research of Wiklund and Shepherd (2015). This shows that in the context of emerging and developing economies, business efficiency increases when EO increases in an environment considered stable and benign. This result also implies for business executives to consider implementing EO, aiming to take risks and lead the way, especially in the current environment without too fierce competition. Therefore, if businesses do not implement the strategy of a leader and proactively enter the market and accept risks in using more resources to find and implement new opportunities in the current non-pressured environment, it will be a challenge to achieve outstanding business performance.

Control variables also contribute to the interpretation of the model. In particular, the age of businesses tends to be negative to EO. The influence coefficient in this case is -0.179 ( $p$ value $<0.05$ ). However, the positive effect of firm size on performance has not been confirmed in this research result. This result shows that seemingly younger businesses or businesses of bigger scale have a tendency for faster growth and therefore, have higher business efficiency than more mature businesses (according to the business owners' subjective viewpoints). 


\section{Conclusions}

The initial findings from this study suggest that the influence of entrepreneurship is one of the key factors affecting the business performance of SMEs even in the least competitive environment. In particular, the role of pioneering initiatives in new products and markets as well as the ability to adapt to changes (both in terms of business organization, business models and products) is emphasized in meeting market needs and the role of taking risks inarbitrarily to gain new opportunities with higher profit margins. However, based on these key influences, the study did not provide a complete explanation of the role of innovation in business performance, when it was confirmed in most studies (Covin and Slevin, 1989, Johan Wiklund and Shepherd, 2005; Acostaa, Crespob and Collado, 2018).

Nonetheless, the results have contributed to diversifying the documents and materials on the relationship between EO and business performance in transition and emerging economies, which are quite scarce and have not received empirical investigation in the recent time. Our research also provides some implications for businesses practicing $\mathrm{EO}$ and points out some limitations that need to be resolved in the future.

\subsection{Some Implications for Businesses That Practice EO}

First, the level of EO practice based on leadership and the willingness to accept risks under appropriate risk management conditions is a strategic basis to improve the performance of the business. Businesses exhibiting low EO practices will narrow their business in a familiar environment that is difficult to meet new market requirements and without new business opportunities to gain higher profits as well as further risk-prevention from the market. These businesses either use too few resources to invest in new opportunities, thus limiting their growth and development.

Second, EO is not the only way for businesses to increase business efficiency but it is a strategic way for businesses to overcome environmental constraints and limited resources to be able to gain a higher competitive advantage and thus, achieve higher business performance.

Third, innovation is always a matter of businesses that need to practice in practice to meet the increasing demands and demands of the market. Therefore, with the available research resources, we do not have enough bases to conclude on the positive impact of the innovation aspect on business performance while being fully aware of the role of this factor. This is also an issue that needs to be further studied with a larger sample size with the control of industry characteristics and operating environment in connection with technological factors as well as consideration of time delay characteristics, when considering the impact of innovation on the business performance of small and medium enterprises.

Finally, besides the need to continue researching the impact of innovation in entrepreneurship tendencies mentioned above, we also recognize some limitations on our study.

\subsection{Limitations and Future Research Direction}

First, our research has shown the positive relationship of EO to the business performance of SMEs; however, these results only stop at the initial identification of the direct relationship without further explanation or clarification of any mechanism or method by which EO can positively make an impact on business performance, in addition to the considered environmental factors. This issue requires further studies on the intermediate or regulatory effects of contextual factors on which the business operates, such as organizational culture, learning mechanisms at the institutional level for entrepreneur spirit orientation, or the use of resources (the willingness to be bold, take risk and pioneer) to ensure the realization of entrepreneurial direction into outstanding business performance.

Second, we have identified a positive correlation between innovation and business performance; however, we have not been able to conclude a positive relationship between them as a result of most existing research. The question remains whether commercial enterprises do not exhibit significant innovation factors between firms with low business results and high business results, or due to the too modest size of research samples to arrive at a conclusion. This issue is a limitation and also a suggestion for further research to clarify on a larger sample size. In addition, existing studies mainly focus on investigating industrial firms with the justification that these firms are the best study subjects for investigating innovation (for instance, Huges $P$ et al, 2018). However, this can cause a bias in the study, as different industries have different levels of innovation. Therefore, examining industrial elements in EO and business performance can help better explain this relationship.

Third, like most other studies, this study also faces the issue of survivor bias. Along with the advantages, there is also the possibility of failure risk for businesses practicing EO, putting a lot of resources for innovation, expanding markets and taking on venture capital opportunities. Taking this into account, our conclusions are only generalized for the businesses that still remain in operation.

Finally, looking at the influence of business environmental factors in the relationship between EO and performance, the use of the current scale has not allowed the clarification of the different impact of a micro or macroeconomic environment on the application of EO to provide multiple suggestions for the issue. Therefore, unidirectional effects may not cover all the effects of EO impact mechanism on operational efficiency that need to be studied in the direction of configuration with 
multidimensional analysis. These are also implications for future research needed for the area of SMEs in Vietnam today.

\section{REFERENCES}

[1] Acosta A, Crespo A, Agudo J, 2018. Effect of market orientation, network capability and entrepreneurial Orientation on international performance of small and medium enterprises (SMEs). International Business Review 27 (2018) 1128-1140

[2] Brown, S.L., Eisenhardt, K.M., 1998. Competing on the Edge. Harvard Business School Press, Boston, MA.

[3] Brush, C.G., Greene, P.G., Hart, M.M., 2001. From initial idea to unique advantage: the entrepreneurial challenge of constructing a resource base. Acad. Manage. Exec. 15 (1), 64-78

[4] Chandler, G.N., Hanks, S.H., 1994. Founder competence, the environment, and venture performance.

Entrepreneurship Theory \& Practice. 18 (3), 77-89.

[5] Covin, J.G., Slevin, D.P., 1991. A conceptual model of entrepreneurship as firm behavior. Entrepreneurship Theory \& Practice., (Fall), 7-25.

[6] Fombrun, C.J., Wally, S., 1989. Structuring small firms for rapid growth. Journal Business Venturing 4, 107-122

[7] Hamel, G., 2000. Leading the Revolution. Harvard University Press, Cambridge, MA.

[8] Gao Y, Geb B, Lang X, Xu X (2018). Impacts of proactive orientation and entrepreneurial strategy on entrepreneurial performance: An empirical research. Technological Forecasting \& Social Change 135 (2018) 178 -187

[9] Hart, S.L., 1992. An integrative framework for strategy-making processes. Academic Management. Rev. 17 (2), 327-351.

[10] Hughes P, Hodgkinson, Hughes and Arshad D 2018. Explaining the entrepreneurial orientation-performance relationship in emerging economies: The intermediate roles of absorptive capacity and improvisation. Asia Paciic Journal Management. DOI 10.1007/s10490-017-9539-7
[11] Knight, G.A., 1997. Cross-cultural reliability and validity of a scale to measure firm entrepreneurial orientation. Journal Business Venturing 12, 213-225.

[12] Lumpkin, G., Dess, G.G., 1996. Clarifying the entrepreneurial orientation construct and linking it to performance.

[13] March, J.G., 1991. Exploration and exploitation in organizational learning. Organization Science. 2, 71-87 Academic Management Rev. 21 (1), 135-172.

[14] McGrath, R.G., 2001. Exploratory learning, innovative capacity, and managerial oversight. Academic Management Journal, 44, 118-131.

[15] Miller, D., 1983. The correlates of entrepreneurship in three types of firms. Management Science. 29, 770-791.

[16] Namen, J.L., Slevin, D.P., 1993. Entrepreneurship and the concept of fit: a model and empirical tests. Strategic Management. J. 14, 137-153.

[17] Nguyen, T.T. Mai, 2009. Enhancing Entrepreneurial Orientation, A stimulus for business development in Vietnam during the Economics Recession. International Vision, 13, 85-95.

[18] Smart, D.T., Conant, J.S., 1994. Entrepreneurial orientation, distinctive marketing competencies and organizational performance. J. Appl. Business. Res. 10, 28-38

[19] Schumpeter, J., 1934. The Theory of Economic Development. Harvard Univ. Press, Cambridge, MA.

[20] Tsai, W.M.H., MacMillan, I.C., Low, M.B., 1991. Effects of strategy and environment on corporate venture success in industrial markets. Journal of Business. Venturing 6 (1), 928

[21] Zahra, S., 1991. Predictors and financial outcomes of corporate entrepreneurship: an explorative study. J. Business Venturing 6, 259-285.

[22] Zahra, S.A., 1993b. Environment, corporate entrepreneurship, and financial performance: a taxonomic approach. J. Business Venturing 8, 319-340.

[23] Zahra, S., Covin, J., 1995. Contextual influence on the corporate entrepreneurship-performance relationship: a longitudinal analysis. J. Bus. Venturing 10, 43-58.

[24] Wiklund, J., 1999. The sustainability of the entrepreneurial orientation-performance relationship. Entrepreneurship Theory \&. Practice. 24 (1), 37-48. 